\title{
Correlation between Upper Extremity Strength and the Oral Health of Stroke Patients
}

\author{
Geun Su Lee ${ }^{1}$, Ji Sun Lee ${ }^{2}$, Eun Young Kang ${ }^{1}$ \\ ${ }^{1}$ Department of Rehabilitation Medicine, Kwangju Christian Hospital, Gwangju, ${ }^{2}$ Saeum Dental Hospital, Gwangju, Korea
}

Objective: The objectives of this study were to evaluate the correlation between upper extremity strength and oral health in stroke patients, as well as to determine the need for improvement in oral health measures, including rehabilitation to enhance upper extremity strength, and education and training for patients and their guardians related to oral hygiene.

Methods: To evaluate the oral health of stroke patients, we performed an examination of oral health and survey of oral hygiene behavior. Using the Oral Health Assessment Tool, an examiner evaluated oral health using a dental mirror. The upper extremity muscle strength was also assessed using the Manual Muscle Testing (MMT) grading system.

Results: Patients with higher-grade upper extremity muscle strength had better oral health. Patients with higher MMT grades were more likely to brush their teeth independently, and more often, compared to those with lower grades.

Conclusion: The MMT grade of patients with chronic stroke was significantly related to the oral health. Therefore, to improve oral health, patients should receive oral hygiene education and rehabilitation to increase their MMT grade. Combined efforts by rehabilitation and dental departments are required to improve the oral health of chronic stroke patients.

Keywords: oral health, stroke, muscle strength

\section{Introduction}

The incidence of cerebrovascular diseases is increasing due to hypertension, diabetes, obesity, stress, lack of exercise, poor dietary habits, and smoking. According to the 2018 Stroke Fact Sheet in Korea, published by the Korean Stroke Society, the number of stroke patients in Korea in 2014 was 690,000 (males: 380,000, 55.1\%; females: 310,000, 44.9\%),

\section{Corresponding author Eun Youn Kang}

E-mail: eykang74@hanmail.net

(iD) https://orcid.org/0000-0001-6805-5727

Received August 29, 2021, Revised September 27, 2021, Accepted September 29, 2021 with an average annual increase of 105,000 patients. Additionally, the prevalence of stroke increased with advancing age; the prevalence rate in those aged over 75 years was 2-fold higher than for those aged 55-74 years and 13-fold higher than for those aged 19-55 years [1].

According to Health at a Glance 2017, published by the Organisation for Economic Co-operation and Development, the 30-day fatality rate among hospitalized patients with ischemic stroke over 45 years of age was $3.9 \%$, which steadily decreased from $5.0 \%$ in 2008 . The 30 -day fatality rate for in-patients with hemorrhagic stroke also reduced from $19.8 \%$ to $17.1 \%$ during the same period [2]. The lifespan of stroke patients is increasing due to advances in medical technology; therefore, it is critical to improve the quality of life of these patients.

Copyright (C) 2021. Korean Academy of Preventive Dentistry. All rights reserved.

This is an Open Access article distributed under the terms of the Creative Commons Attribution Non-Commercial License (http://creativecommons.org/licenses/ by-nc/4.0) which permits unrestricted non-commercial use, distribution, and reproduction in any medium, provided the original work is properly cited. 
Symptoms of stroke, such as paralysis, impaired consciousness, impaired communication, stiffness, and cognitive impairment impair the ability of patients to carry out oral hygiene tasks [3]. Aspiration pneumonia is a significant cause of death after stroke due to medical complications. The risk of aspiration pneumonia increases with poor oral hygiene [4,5]. However, the quantity of potential respiratory pathogens is reduced through proper oral care, and aspiration pneumonia is prevented by improving the swallowing reflex and cough sensitivity [6]. Therefore, professional oral care, including periodic dental treatment, tooth brushing after eating, and denture cleaning, reduce the risk of aspiration pneumonia [7].

Many activities of daily living depend on normal arm function, including tooth brushing. Muscle strength is essential for activities of daily living, and muscle weakness due to damaged upper motor neurons is common after stroke [8]. Manual muscle testing (MMT) is widely used to evaluate the arm and leg strength of stroke patients [9].

Although poor oral hygiene has been reported in stroke pa- tients [3], few studies have examined the relationship between upper extremity movement and oral health. Therefore, we examined the arm strength of chronic stroke patients using the MMT, to determine the effects of upper extremity muscle weakness on oral health. In addition, we evaluated measures to improve the oral hygiene of chronic stroke patients.

\section{Materials and Methods}

\section{Target population}

This study included 60 patients (males: $n=26,43 \%$; females: $\mathrm{n}=34,57 \%$; age range: $40-85$ years; mean age: 62 years) with chronic stroke (6-12 months before the study) who were admitted to the Department of Rehabilitation Medicine of a general hospital in South Korea.

The Institutional Review Board of Kwangju Christian hospital approved the study and signed (No. KCHIRB-D-2019-096), written informed consent forms were obtained. The partic-

Table 1. Oral Health Assessment Tool for dental screening

\begin{tabular}{|c|c|c|c|c|}
\hline Category & $0=$ Healthy & $1=$ Changes $*$ & $2=$ Unhealthy $*$ & Category scores \\
\hline Lips & Smooth, pink, moist & Dry, chapped, or red at corners & $\begin{array}{l}\text { Swelling or lump, white/red/ } \\
\text { ulcerated patch; bleeding/ } \\
\text { ulcerated at corners }\end{array}$ & \\
\hline Tongue & Normal, moist roughness, pink & Patchy, fissured, red, coated & $\begin{array}{l}\text { Patch that is red and/or white, } \\
\text { ulcerated, swollen }\end{array}$ & \\
\hline $\begin{array}{l}\text { Gums and } \\
\text { tissues }\end{array}$ & Pink, moist, smooth, no bleeding & $\begin{array}{l}\text { Dry, shiny, rough, red, swollen, } \\
\text { one ulcer/sore spot under } \\
\text { dentures }\end{array}$ & $\begin{array}{l}\text { Swollen, bleeding, ulcers, white/ } \\
\text { red patches, generalized } \\
\text { redness under dentures }\end{array}$ & \\
\hline Saliva & $\begin{array}{l}\text { Moist tissues, watery and free } \\
\text { flowing saliva }\end{array}$ & $\begin{array}{l}\text { Dry, sticky tissues, little saliva } \\
\text { present, resident thinks they } \\
\text { have a dry mouth }\end{array}$ & $\begin{array}{l}\text { Tissues parched and red, very } \\
\text { little/no saliva present, saliva is } \\
\text { thick, resident thinks they have } \\
\text { a dry mouth }\end{array}$ & \\
\hline $\begin{array}{l}\text { Natural teeth } \\
\text { Yes/No }\end{array}$ & $\begin{array}{l}\text { No decayed or broken } \\
\text { teeth/roots }\end{array}$ & $\begin{array}{l}\text { 1-3 decayed or broken } \\
\text { teeth/roots or very worn down } \\
\text { teeth }\end{array}$ & $\begin{array}{l}4+\text { decayed or broken teeth/roots, } \\
\text { or very worn down teeth, or } \\
\text { less than } 4 \text { teeth }\end{array}$ & \\
\hline $\begin{array}{l}\text { Dentures } \\
\text { Yes/No }\end{array}$ & $\begin{array}{l}\text { No broken areas or teeth, } \\
\text { dentures regularly worn, and } \\
\text { named }\end{array}$ & $\begin{array}{l}1 \text { broken area/tooth or dentures } \\
\text { only worn for } 1-2 \text { hrs daily, or } \\
\text { dentures not named, or loose }\end{array}$ & $\begin{array}{l}\text { More than } 1 \text { broken area/tooth, } \\
\text { denture missing or not worn, } \\
\text { loose and needs denture } \\
\text { adhesive, or not named }\end{array}$ & \\
\hline $\begin{array}{l}\text { Oral } \\
\text { cleanliness }\end{array}$ & $\begin{array}{l}\text { Clean and no food particles or } \\
\text { tartar in mouth or dentures }\end{array}$ & $\begin{array}{l}\text { Food particles/tartar/plaque in } \\
1-2 \text { areas of the mouth or on } \\
\text { small area of dentures or } \\
\text { halitosis (bad breath) }\end{array}$ & $\begin{array}{l}\text { Food particles/tartar/plaque in } \\
\text { most areas of the mouth or on } \\
\text { most of dentures or severe } \\
\text { halitosis (bad breath) }\end{array}$ & \\
\hline Dental pain & $\begin{array}{l}\text { No behavioural, verbal, or } \\
\text { physical signs of dental pain }\end{array}$ & $\begin{array}{l}\text { Are verbal \&/or behavioural } \\
\text { signs of pain such as pulling at } \\
\text { face, chewing lips, not eating, } \\
\text { aggression }\end{array}$ & $\begin{array}{l}\text { Are physical pain signs (swelling } \\
\text { of cheek or gum, broken teeth, } \\
\text { ulcers), as well as verbal \%/or } \\
\text { behavioural signs (pulling at } \\
\text { face, not eating, aggression) }\end{array}$ & \\
\hline
\end{tabular}


ipants were informed of the study purpose and procedures prior to enrollment.

\section{Research methodology}

We performed oral examinations and conducted a survey to evaluate oral condition and hygiene behavior, respectively. The survey responders were patients or their guardians. A single examiner performed the oral examination using the Oral Health Assessment Tool (OHAT) [10] and a dental mirror.

\section{1) Oral health examination}

Using the OHAT, eight categories of oral health were examined, including lips, tongue, periodontal region, saliva, teeth, denture, cleanliness, and pain. Each category was scored on 2-point scale (total score: 0-16). Higher scores correlated with worse oral health (Table 1).

\section{2) Survey for oral hygiene behaviors}

The survey asked participants whether they were able to brush their teeth by themselves, whether they used oral hygiene aids (such as floss, an interdental toothbrush, oral rinse, or an electric toothbrush), and the frequency of tooth brushing. The patients were also asked to specify the aspects that they considered significant when choosing or visiting a dental clinic.

\section{3) Muscle strength evaluation}

We used the MMT to evaluate the muscle strength of 60 chronic stroke patients based on upper extremity movements [11] (Table 2).
4) Data analysis

We performed t-tests using SPSS software (version 12.0; SPSS Inc., Chicago, IL, USA) and evaluated the homogeneity of variance using Levene's test. Pearson correlation analysis was performed to evaluate the relationship between MMT grade and oral health.

\section{Results}

\section{Participant characteristics}

The study participants were 60 chronic stroke patients (males: $n=26,43 \%$; females: $n=34,57 \%$ ) aged $40-85$ years (40-50 years: $n=7,11.6 \% ; 51-60$ years: $n=18,30 \% ; 61-70$ years: $n=17,28.3 \%$; 71-80 years: $n=14,23.3 \%$; $81-85$ years: $\mathrm{n}=4,6.8 \%)$. Patients aged $51-70$ years $(\mathrm{n}=35,58.3 \%)$ accounted for more than half of the hospitalized patients (Table 3 ).

Table 4. Oral health assessment in chronic stroke patients

\begin{tabular}{lccc}
\hline \multicolumn{1}{c}{ Category } & $0=$ Healthy & 1 =Changes & 2 = Unhealthy \\
\hline Lips & $20(33.3)$ & $35(58.3)$ & $5(8.4)$ \\
Tongue & $34(56.7)$ & $21(35.0)$ & $5(8.3)$ \\
Gums and surrounding & $27(45.0)$ & $29(48.3)$ & $4(6.7)$ \\
$\quad$ tissues & & & \\
Saliva & $48(80.0)$ & $12(20.0)$ & $0(0.0)$ \\
Natural teeth & $32(53.3)$ & $20(33.3)$ & $8(13.4)$ \\
Denture & $0(0.0)$ & $0(0.0)$ & $5(100.0)$ \\
Oral cleanliness & $25(41.7)$ & $21(35.0)$ & $14(23.3)$ \\
Dental pain & $60(100)$ & $0(0.0)$ & $0(0.0)$ \\
\hline
\end{tabular}

Values are presented as number (\%).

Table 2. Manual Muscle Testing grading system

\begin{tabular}{lcl}
\hline \multicolumn{1}{c}{ Grade } & Percentage & Description \\
\hline 5 (Normal) & $100 \%$ & Complete range of motion against gravity with full resistance \\
4 (Good) & $75 \%$ & Complete range of motion against gravity with some resistance \\
3 (Fair) & $50 \%$ & Complete range of motion against gravity with no resistance \\
2 (Poor) & $25 \%$ & Complete range of motion with gravity eliminated \\
1 (Trace) & $10 \%$ & Evidence of slight contractility with no evidence of joint motion even with gravity eliminated \\
0 (No movement) & $0 \%$ & No evidence of muscle contractility \\
\hline
\end{tabular}

Table 3. Age and sex distribution of chronic stroke patients

\begin{tabular}{|c|c|c|c|c|c|c|}
\hline \multirow{2}{*}{ Sex } & \multicolumn{5}{|c|}{ Age (y) } & \multirow{2}{*}{ Total } \\
\hline & $40-50$ & $51-60$ & $61-70$ & $71-80$ & 81-85 & \\
\hline Male & $2(3.3)$ & 8 (13.3) & $12(20.0)$ & $4(6.7)$ & $0(0.0)$ & $26(43.3)$ \\
\hline Female & $5(8.3)$ & 10 (16.7) & $5(8.3)$ & $10(16.7)$ & $4(6.7)$ & 34 (56.7) \\
\hline Total & 7 (11.6) & $18(30)$ & $17(28.3)$ & $14(23.4)$ & $4(6.7)$ & 60 (100.0) \\
\hline
\end{tabular}

Values are presented as number (\%). 


\section{Oral health}

We scored the eight categories of oral health as 0 (healthy), 1 (changes), or 2 (unhealthy) (Table 4).

Slight changes in the lips were seen in 35 patients $(58.3 \%)$ due to dryness, scored as 1 , and 5 patients $(8.4 \%)$ had a score of 2 for inflammation and ulceration in the corners of the lips. For the tongue, 21 patients $(35.0 \%)$ had a score of 1 due to a cracked or red-colored back of the tongue, and $5(8.3 \%)$ had a score of 2 due to white tongue lesions. For the periodontal region (gums and tissues), 29 patients (48.3\%) had a score of 1 due to red and swollen gums, and $4(6.7 \%)$ had a score of 2 due to loose teeth and swollen gums around more than seven teeth. Twelve patients $(20.0 \%)$ had a score of 1 for saliva due to oral dryness. For the natural teeth, 20 patients $(33.3 \%)$ had a score of 1 due to three or fewer dental caries, and 8 (13.4\%) had a score of 2 due to four or more dental caries and significantly worn teeth. No patients were completely edentulous. Five patients used dentures before stroke surgery, and all used partial dentures. Three patients had ill-fitting dentures due to tooth extraction for tracheal intubation before the stroke surgery. Two patients could not wear dentures due to periodontal changes (because the dentures had not been worn for a long time). For oral cleanliness, 21 patients $(35.0 \%)$ had a score of 1 due to food debris stuck between teeth or tartar in 1-2 teeth, and $14(23.3 \%)$ had a score of 2 due to plaque and calculus on the teeth. All 60 patients scored 0 for dental pain (i.e., had no verbal or physical signs of pain).

Table 5. OHAT score and MMT grade by sex

\begin{tabular}{llrc}
\hline Sex & Value & $\begin{array}{c}\text { OHAT Score } \\
(0-16)\end{array}$ & $\begin{array}{c}\text { Upper extremity } \\
\text { MMT grade (0-5) }\end{array}$ \\
\hline Male & $26(43.0)$ & $3.5 \pm 2.25$ & $3.46 \pm 1.23$ \\
Female & $34(57.0)$ & $3.79 \pm 2.16$ & $3.05 \pm 1.17$ \\
Total & $60(100.0)$ & $3.67 \pm 2.18$ & $3.23 \pm 1.39$ \\
\hline
\end{tabular}

Values are presented as number (\%) or mean \pm standard deviation. OHAT: oral health assessment tool, MMT: manual muscle testing.

Table 6. Correlation between OHAT score and MMT grade

\begin{tabular}{llcc}
\hline & & $\begin{array}{c}\text { OHAT } \\
\text { score }\end{array}$ & $\begin{array}{c}\text { Upper extremity } \\
\text { MMT grade }\end{array}$ \\
\hline \multirow{2}{*}{ OHAT score } & Correlation coefficient & 1 & -0.547 \\
& p-value & & 0.000 \\
& $\mathrm{n}$ & 60 & 60
\end{tabular}

OHAT: Oral Health Assessment Tool, MMT: manual muscle testing.

\section{OHAT scores and upper extremity muscle strength by sex}

No significant difference was observed in the average OHAT scores of 26 male and 34 female patients (3.5 and 3.79, respectively; $p>0.05)$. The average OHAT score for all patients was 3.67 (Table 5).

The average MMT grades for male and female patients were 3.46 and 3.05 , respectively, with a combined average grade of 3.23 .

\section{Correlation between upper extremity muscle strength and oral health}

Upper extremity muscle strength grade and oral health showed a significant moderate correlation $(\mathrm{r}=-0.547)$. Higher upper extremity muscle strength grades were associated with lower OHAT scores and better oral health (Table 6).

We investigated the correlations between OHAT categories and upper extremity muscle strength (Table 7). A significant negative correlation was observed between upper extremity muscle strength grade and category of oral cleanliness $(\mathrm{r}=-$ 0.605 ). Oral cleanliness was evaluated on the basis of food debris, plaque, and tartar. Higher upper extremity muscle strength grades were associated with lower oral cleanliness scores, indicating good oral condition (Table 8).

Table 7. $p$-value for the scores on the Oral Health Assessment Tool categories

\begin{tabular}{ll}
\hline \multicolumn{1}{c}{ Category } & p-value \\
\hline Lips & 0.071 \\
Tongue & 0.057 \\
Gums and surrounding tissues & 0.052 \\
Saliva & 0.068 \\
Natural teeth & 0.062 \\
Denture & 0.069 \\
Oral cleanliness & $0.000^{*}$ \\
Dental pain & 0.067 \\
\hline
\end{tabular}

Table 8. Correlation between oral cleanliness and upper extremity MMT grade

\begin{tabular}{llcc}
\hline & & $\begin{array}{c}\text { Oral } \\
\text { cleanliness }\end{array}$ & $\begin{array}{c}\text { Upper extremity } \\
\text { MMT grade }\end{array}$ \\
\hline Oral & Correlation coefficient & 1 & -0.605 \\
cleanliness & $p$-value & & 0.000 \\
& $n$ & 60 & 60 \\
\hline
\end{tabular}

MMT: manual muscle testing. 


\section{Oral health behavior analysis}

1) Tooth brushing behavior by upper extremity muscle strength grade

The survey revealed that 33 patients $(55 \%)$ brushed their teeth independently, while 27 (45\%) were assisted by their guardians; there was a significant difference in muscle strength grade between these groups (3.76 and 2.59, respectively) (Table 9).

\section{2) Frequency of tooth brushing}

The survey revealed that the number of participants who brushed their teeth daily, twice a day, three times a day, and after every meal was $18(30 \%), 14(23.3 \%), 18(30 \%)$, and 10 (16.7\%), respectively (Table 10$)$.

\section{3) Correlation between OHAT scores and frequency of tooth brushing}

There was a significant negative correlation between OHAT scores and frequency of tooth brushing. Patients who brushed their teeth more frequently had lower OHAT scores (Table 11). The results showed that tooth brushing had a significant correlation with OHAT scores $(\mathrm{r}=-0.754)$.

Table 9. Upper extremity MMT grade by tooth brushing ability

\begin{tabular}{ccc}
\hline Toothbrush ability & Value & Upper extremity MMT grade \\
\hline Independent & $33(55.0)$ & $3.76 \pm 1.03$ \\
Dependent & $27(45.0)$ & $2.59 \pm 1.53$
\end{tabular}

Values are presented as number (\%) or mean \pm standard deviation. MMT: manual muscle testing.

Table 10. Tooth brushing frequency in chronic stroke patients

\begin{tabular}{cc}
\hline Tooth brushing frequency & $\mathrm{n}(\%)$ \\
\hline Once a day & $18(30.0)$ \\
Twice a day & $14(23.3)$ \\
Three times a day & $18(30.0)$ \\
After every meal & $10(16.7)$ \\
\hline
\end{tabular}

Table 11. Correlation between OHAT scores and tooth brushing frequency

\begin{tabular}{llcc}
\hline & & $\begin{array}{c}\text { OHAT } \\
\text { score }\end{array}$ & $\begin{array}{c}\text { Tooth brushing } \\
\text { frequency }\end{array}$ \\
\hline OHAT score & Correlation coefficient & 1 & -0.754 \\
& p-value & & 0.000 \\
& $\mathrm{n}$ & 60 & 60 \\
\hline
\end{tabular}

OHAT: Oral Health Assessment Tool.
4) Correlation between upper extremity muscle strength grade and frequency of tooth brushing

A significant correlation was observed between the upper extremity muscle strength grade and frequency of tooth brushing (Table 12). Higher upper extremity muscle strength grades were associated with more frequent tooth brushing $(\mathrm{r}=-$ $0.742)$.

\section{Analysis of dental clinic visits}

The dental clinic most frequently visited by the stroke patients was the one closest to the hospital where they were hospitalized $(51.7 \%)$, followed by university dental hospitals (26.7\%) (Table 13).

The major factor in clinic choice was distance (65\%), followed by availability of necessary devices and equipment (21.7\%). However, some patients selected university dental hospitals because they were not accepted by the local dental clinic (Table 14).

Table 12. Correlation between upper extremity MMT and tooth brushing frequency

\begin{tabular}{llcc}
\hline & & $\begin{array}{c}\text { Upper extremity } \\
\text { MMT grade }\end{array}$ & $\begin{array}{c}\text { Toth brushing } \\
\text { frequency }\end{array}$ \\
\hline Upper & Correlation coefficient & 1 & 0.742 \\
extremity & p-value & & 0.000 \\
MMT grade & $\mathrm{n}$ & 60 & 60 \\
\hline
\end{tabular}

MMT: manual muscle testing.

Table 13. Dental care utilization by stroke patients

\begin{tabular}{ll}
\hline Dental care utilization & $\mathrm{n}(\%)$ \\
\hline Close to the hospital & $31(51.7)$ \\
Previously visited & $13(21.7)$ \\
University dental hospital & $16(26.7)$ \\
Total & $60(100.0)$ \\
\hline
\end{tabular}

Table 14. Reasons cited by stroke patients for dental clinic choice

\begin{tabular}{lc}
\hline \multicolumn{1}{c}{ Reasons } & $\mathrm{n}(\%)$ \\
\hline Quality of dental care & $5(8.3)$ \\
Distance & $39(65.0)$ \\
Modern and up-to-date equipment & $13(21.7)$ \\
Referral & $3(5.0)$ \\
Total & $60(100.0)$ \\
\hline
\end{tabular}




\section{Discussion}

The oral cavity, as the primary digestive system, is extremely important for health. Diseases of the oral cavity can be systemic, and there is a significant correlation of the incidence of cardiovascular diseases with periodontitis and tooth loss [12].

The incidence of stroke is gradually increasing. Stroke may lead to serious physical, mental, and social problems, making oral care more difficult and thus compromising oral health [13]. Given the longer life expectancy of chronic stroke patients as a result of advances in medical technology, it is necessary to focus on the oral health of these patients.

We examined the oral health of patients using the OHAT, which evaluates oral health in eight domains, including lips, tongue, periodontal region, saliva, teeth, denture use, oral cleanliness, and pain. The OHAT allows rapid evaluation of oral health, even among patients with cognitive impairment. Assessment of oral care using the OHAT, at hospital admission and discharge, can guide oral healthcare plans. Considering these factors, we examined the oral health of patients using the OHAT.

The mean OHAT score of our 60 participants was $3.67 \pm$ 2.18 (0: good; 1-5: oral care intervention necessary). A total score of $\geq 6$, or a score of $\geq 1$ in the categories of "gums and surrounding tissues", "natural teeth", or "toothache", warrant a dental check-up [10]. Therefore, most chronic stroke patients need oral care. The most significant changes in oral care were dry and cracked lips, red swollen gums, dry mouth, food debris in the mouth, and dental plaque. It is necessary to identify changes in oral health based on OHAT scores, and to take action as appropriate. Scores of 1 and 2 in any category require advice from the dentist and a dental check-up, respectively.

Patients who have difficulty in tooth brushing due to wounds or dental appliances should be managed via oral hygiene intervention and mouthwash. The use of chlorhexidine gluconate is required for prosthetic inflammation, candida infection, and gingivitis. Cognitively impaired patients may benefit from a demonstration of a simplified tooth brushing process or the hand-over-hand technique, in which teaching tooth brushing is achieved by holding their hands, rather than through verbal instructions.

The MMT is a highly reliable method for testing the muscle strength of stroke patients [9]. Muscle strength is graded on the basis of the degree of resistance overcome by the muscle. Muscle strength is scored from 0 to 5 based on three factors: gravity, resistance, and range of joint movement. The MMT does not require any particular tools, and can be used by examiners with the requisite education and knowledge. Therefore, the MMT can be used to evaluate muscle strength in a large volume of patients [10]. Notably, the MMT cannot detect subtle changes in muscle strength, which is a significant limitation [14]. In this study, the average upper extremity muscle strength grade for the stroke patients was $3.23 \pm 1.39$ (i.e., upper extremity can be lifted without any external resistance).

The average upper extremity muscle strength grades were $3.76 \pm 1.03$ and $2.59 \pm 1.53$ for patients who brushed their teeth independently and those who were dependent on their guardians for tooth brushing, respectively.

Upper extremity muscle strength grades of 4 and 5 indicate that patients are able to independently brush their teeth. Grades of $\leq 2$ indicate that the patient requires assistance for tooth brushing. Some of our grade 3 patients were able to independently brush their teeth, whereas others were not. Therefore, an upper extremity muscle strength grade of $\geq 3$ may predict independent tooth brushing. Additionally, there was a significant correlation between oral health and upper extremity muscle strength grade, where higher grades were associated with better oral health.

No significant correlation was observed between the upper extremity muscle strength grade and OHAT category of "natural teeth", which evaluates dental caries, residual tooth root, and the number of teeth (cutoff of $<4$ ). Because we only included patients who suffered a stroke within the past 6-12 months, an inadequate amount of time had passed to assess the effects of poor tooth brushing on oral health. Therefore, longer follow-up is required in future studies.

A significant correlation was observed between the upper extremity muscle strength grade and oral cleanliness. The OHAT category of "oral cleanliness" evaluates food debris, dental plaque, and tartar. Plaque buildup leads to periodontal disease [15]. Prevention and alleviation of chronic inflammatory periodontal disease relies on effective daily plaque removal from the tooth surface [16]. Therefore, plaque and residual food debris should be removed using various dental aids, such as manual or electric toothbrushes [17]. Independent tooth brushing is possible only with a high degree of upper extremity muscle strength. It is likely that more frequent tooth brushing improves oral cleanliness.

Previous studies showed that dental plaque causes caries and gingival inflammation [18-20]. Plaque forms on the tooth surface due to a bacterial film consisting of saliva and glycoprotein. The bacteria on the tooth surface may form a colony. Dental plaques alter the bacterial flora and chemical composition of the tooth surface $[21,22]$. Moreover, if oral hygiene measures (i.e., tooth brushing) are discontinued, partial gingivitis forms within 4-11 days, and spreads to the entire gum within 2-3 weeks. However, resumption of oral hygiene measures profoundly improves the gingival condition [22]. Although 
the optimal frequency of plaque removal necessary to maintain gingival health is controversial, evidence from the current and previous studies suggests that plaque formation is reduced with increased frequency of application of oral hygiene measures, such as tooth brushing [23]. Therefore, rehabilitation, which improves the upper extremity muscle strength of chronic stroke patients, is crucial for preventing plaque formation, improving independence in activities of daily living, and maintaining healthy gingiva and teeth.

The survey results revealed that the number of participants who brushed their teeth daily, twice a day, three times a day, and after every meal was $18(30 \%), 14(23.3 \%), 18(30 \%)$, and $10(16.7 \%)$, respectively.

None of the patients used oral hygiene products, such as floss, an interdental toothbrush, mouthwash, or an electric toothbrush, except for manual toothbrushes. A significant correlation was observed between the OHAT scores and frequency of tooth brushing, with more frequent tooth brushing corresponding to better oral health.

The dental clinic most frequently visited by the stroke patients was the one closest to the hospital where they were hospitalized (51.7\%), followed by university dental hospitals (26.7\%). The distance to the dental clinic was the most important factor in the choice of dental clinic (65\%).

Patients who visited university dental hospitals made their choice based on the availability of appropriate medical equipment, or were referred by other clinics. To improve the access of chronic stroke patients to dental care at nearby clinics, it is essential to provide continuous professional education and training to dentists working in these clinics regarding the diagnosis and treatment of such patients. Additionally, patients being treated at university dental hospitals may benefit from a systematic policy of patient transfers and referrals.

Our study results demonstrated that chronic stroke patients with high-grade upper extremity muscle strength had better oral health, probably because such patients could independently brush their teeth.

A strong correlation was observed between upper extremity muscle strength grade and oral cleanliness, where tooth brushing is critical for preventing tartar buildup and removing food debris and plaque. Therefore, the upper extremity muscle strength of chronic stroke patients significantly influences their oral health. For patients with an upper extremity muscle strength grade of $\leq 2$, guardians should be educated regarding tooth brushing. This education should extend to grade 3 patients and their guardians, as well as to patients of $\geq$ grade 4 . Well-designed systems and policies are required to help chronic stroke patients and their guardians to improve their oral hygiene.

\section{Conclusion}

The purpose of this study was to investigate the correlation between oral health and upper extremity muscle strength grade in 60 chronic stroke patients hospitalized at the Department of Rehabilitation Medicine of a general hospital in South Korea. Based on the MMT grade and OHAT scores, we drew several conclusions. First, there was no significant correlation between sex and oral health. The OHAT score for all patients was $3.67 \pm 2.18$, and the most frequent changes included dry and cracked lips, dry mouth, food debris in the mouth, mild plaque, gingivitis, and dental caries in less than three teeth. Second, the average upper extremity muscle strength grade was $3.23 \pm 1.39$. Higher grades correlated with better oral health. Third, the average upper extremity muscle strength grades were $3.76 \pm 1.03$ and $2.59 \pm 1.53$ for patients who independently brushed their teeth and those who were dependent on their guardians, respectively. Patients with higher grades were more likely to brush their teeth independently, and more frequently. Finally, the dental clinic most frequently visited by the stroke patients was the one closest to the hospital where they were hospitalized (51.7\%), followed by university dental hospitals (26.7\%). The distance to the dental clinic was the most important factor in selecting the clinic (65\%).

In conclusion, the upper extremity muscle strength grade of chronic stroke patients significantly influenced their oral health. Rehabilitation and oral hygiene training are necessary for chronic stroke patients to improve their MMT grade and oral hygiene.

\section{Conflict of Interest}

No potential conflict of interest relevant to this article was reported.

\section{ORCID}

Geun Su Lee, https://orcid.org/0000-0003-2131-3148

Ji Sun Lee, https://orcid.org/0000-0003-1561-7794

Eun Young Kang, https://orcid.org/0000-0001-6805-5727

\section{References}

1. Korea Stroke Society. Stroke fact sheet in Korea, 2018. Seoul: Korea Stroke Society; 2018.

2. Organisation for Economic Co-operation and Development. Government at a glance. Yang JJ, translator. Seoul: OECD Korea; 2017:240-1.

3. Kim JH, Han TR. Rehabilitation medicine. Seoul: Gunja pub- 
lication Co; 1999:50-4.

4. Langhorne P, Stott DJ, Robertson L, MacDonald J, Jones L, McAlpine $\mathrm{C}$, et al. Medical complications after stroke: a multicenter study. Stroke 2000;31:1223-9.

5. Sjögren P, Nilsson E, Forsell M, Johansson O, Hoogstraate J. A systematic review of the preventive effect of oral hygiene on pneumonia and respiratory tract infection in elderly people in hospitals and nursing homes: effect estimates and methodological quality of randomized controlled trials. J Am Geriatr Soc 2008;56:2124-30.

6. Watando A, Ebihara S, Ebihara T, Okazaki T, Takahashi H, Asada M, et al. Daily oral care and cough reflex sensitivity in elderly nursing home patients. Chest 2004;126:1066-70.

7. van der Maarel-Wierink CD, Vanobbergen JN, Bronkhorst EM, Schols JM, de Baat C. Oral health care and aspiration pneumonia in frail older people: a systematic literature review. Gerodontology 2013;30:3-9.

8. Ng SS, Shepherd RB. Weakness in patients with stroke: implications for strength training in neurorehabilitation. Phys Ther Rev 2000;5:227-38.

9. Izani MSB, Gofir A, Ismail S. Reability of manual muscle test examination of stroke patient in sardjito hospital. Yogyakarta: Gadjah Mada University; 2014.

10. Nekesa N. Implementing an evidence-based oral health assessment tool in a nursing home [thesis]. [North Dakota]: North Dakota State University; 2013.

11. Helen J. Principles of manual muscle testing, testing the muscles of the upper extremity. In: Hislop HJ, ed. Daniels and Worthingham's muscle testing: techniques of manual examination. 8th ed. St. Louis: Saunders Book Company; 2007:2-8, 61-174

12. Mattila KJ, Pussinen PJ, Paju S. Dental infections and cardiovascular diseases: a review. J Periodontol 2005;76(11
Suppl):2085-8.

13. Pow EH, Leung KC, Wong MC, Li LS, McMillan AS. A longitudinal study of the oral health condition of elderly stroke survivors on hospital discharge into the community. Int Dent $\mathrm{J}$ 2005;55:319-24

14. Yen HC, Luh JJ, Teng T, Pan GS, Chen WS, Hsun CC, et al. Reliability of lower extremity muscle strength measurements with handheld dynamometry in stroke patients during the acute phase: a pilot reliability study. J Phys Ther Sci 2017;29:317-22.

15. Socransky SS. Relationship of bacteria to the etiology of periodontal disease. J Dent Res 1970;49:203-22.

16. Lovdal A, Arno A, Schei O, Waerhaug J. Combined effect of subgingival scaling and controlled oral hygiene on the incidence of gingivitis. Acta Odontol Scand 1961;19:537-55.

17. Suomi JD. Prevention and control of periodontal disease. J Am Dent Assoc 1971;83:1271-87.

18. Lovdal A, Arno A, Waerhaug J. Incidence of clinical manifestations of periodontal disease in light of oral hygiene and calculus formation. J Am Dent Assoc 1958;56:21-33.

19. Schei O, Waerhaug J, Lovdal A, Arno A. Alveolar bone loss as related to oral hygiene and age. J Periodontol 1959;30:7-16.

20. Greene JC. Periodontal disease in India: report of an epidemiological study. J Dent Res 1960;39:302-12.

21. Ritz HL. Microbial population shifts in developing human dental plaque. Arch Oral Biol 1967;12:1561-8.

22. Theilade E, Wright WH, Jensen SB, Löe H. Experimental gingivitis in man. II. A longitudinal clinical and bacteriological investigation. J Periodontal Res 1966;1:1-13.

23. Ariaudo AA, Arnim SS, Greene JC, Löe H. In our opinion: how frequently must patients carry out effective oral hygiene procedures in order to maintain gingival health? J Periodontol. 1971;42:309-13. 